\title{
Risk of Losing Insurance During the Transition into Adulthood Among Insured Youth with Disabilities
}

\author{
Grace Wang · David Grembowski • \\ Carolyn Watts
}

Published online: 11 June 2009

(C) Springer Science+Business Media, LLC 2009

\begin{abstract}
To compare insured youth (age 15-25 years) with and without disabilities on risk of insurance loss. We conducted a cross-sectional study using data from the Survey of Income and Program Participation 2001. Descriptive statistics characterized insured youth who maintained and lost insurance for at least 3 months over a 3 -year time frame. We conducted logistic regression to calculate the association between disability and insurance loss. Adjustment variables were gender, race, ethnicity, age, work or school status, poverty status, type of insurance
\end{abstract}

The online version of the original article can be found under doi:10.1007/s10995-008-0429-y.

The authors sincerely regret that the original publication was in error in reporting that youth with non-severe disabilities on private insurance have higher odds of losing health insurance compared to youth without disabilities. The abstract and last paragraph of the results section have been corrected to report that youth with severe disabilities on private insurance have higher odds of losing health insurance compared to youth without disabilities. The discussion section and the conclusion have also been revised to reflect the correction.

\section{G. Wang $(\bowtie)$}

Institute for Public Health Genetics,

University of Washington, Box 357236, Seattle,

WA 98195-7236, USA

e-mail:wangg@u.washington.edu

D. Grembowski · C. Watts

Department of Health Services,

University of Washington,

Box 357660, Seattle, WA 98195-7660, USA

D. Grembowski

e-mail: grem@u.washington.edu

C. Watts

e-mail:watts@u.washington.edu at study onset, state generosity, and an interaction between disability and insurance type. This study includes 2,123 insured youth without disabilities, 320 insured youth with non-severe disabilities, and 295 insured youth with severe disabilities. Thirty-six percent of insured youth without disabilities lost insurance compared to $43 \%$ of insured youth with non-severe disabilities and $41 \%$ of insured youth with severe disabilities $(P=.07)$. Youth with nonsevere disabilities on public insurance have an estimated $61 \%$ lower odds of losing insurance (OR: 0.39; 95\% CI: $0.16,0.93 ; P=.03$ ) compared to youth without disabilities on public insurance. Further, youth with severe disabilities on public insurance have an estimated $81 \%$ lower odds of losing insurance (OR: 0.19; 95\% CI: $0.09,0.40 ; P<.001$ ) compared to youth without disabilities. When examining youth with private insurance, we find that youth with severe disabilities have 1.63 times higher odds (OR: 1.63; 95\% CI: $1.03,2.57 ; P=.04)$ of losing health insurance compared to youth without disabilities. Insurance type interacts with disability severity to affect odds of insurance loss among insured youth.

Keywords Disability - Youth with special health care needs - Insurance $\cdot$ Transition $\cdot$ Adolescent health

\section{Background}

The U.S. Census Bureau estimated in 2002 that $10 \%$ of youth between the ages of 15 and 24, or approximately 4.1 million youth, had a disability [1]. Youth with disabilities often rate their health as fair or poor, frequently utilize medical care, and require long-term therapy [2-4]. For example, youth with cerebral palsy, spina bifida, and acquired brain injuries in Canada visited physicians 11.5 
times per year and were hospitalized once every 6.8 years, an admission rate 9.0 times that of the general Canadian population [5]. Based on studies among adults with disabilities, uninsured youth with disabilities may be far less likely to obtain care compared to insured youth with disabilities [6-8].

Youth are in the process of transitioning from childhood into young adulthood, a dynamic time when individuals often experience instability in health insurance (hereafter referred to as 'insurance'). Youth have uninsurance rates that are often higher than any other age group with crosssectional prevalence ranging from 20 to $30 \%$ [9-15]. Collins et al. [9] report that the number of uninsured young adults ages 19-29 increased by 2.5 million between 2000 and 2004. Further, Callahan and Cooper's [16] nationally representative study of youth ages 16-24 shows that $56 \%$ of youth with disabilities and $54 \%$ of youth without disabilities reported insurance coverage gaps during a 3-year time frame. This evidence suggests that youth with disabilities may not differentially lose insurance coverage as they age into adulthood. However, these findings do not account for important confounding factors, such as ethnicity or income.

Changes in insurance eligibility during transition into adulthood add another dimension that complicates our understanding of youth's insurance coverage. Children with or without disabilities usually have insurance through parental coverage or through public sources like Medicaid. Williams and Tolbert [17] report that Medicaid supports over a million children and youth under age 21 with severe disabilities and that approximately one of every five children with disabilities has Medicaid coverage. However, sometime between the ages of 19 and 25, parental coverage and Medicaid end resulting in youth "aging out of coverage" [13]. Youth must seek out new coverage through employers or qualify for Medicaid based on stringent adult criteria [17].

It is unclear whether youth in general often lose coverage or whether youth with disabilities are at particular risk for losing coverage. Previous studies have not accounted for potential confounding factors, and the relationship between insurance type and insurance stability remains largely unexplored, especially among youth with disabilities in the midst of transition. This study addresses the questions, are youth with non-severe and severe disabilities more likely to experience insurance loss compared to youth without disabilities? Does the type of insurance that a youth possesses affect the likelihood of loss of coverage? Understanding the risk for insurance loss helps to identify subpopulations who might benefit from insurance reforms. As Short and Graefe [11] note, "efforts to target 'pockets' of the uninsured with incremental coverage reforms must target the right people at the right time."

\section{Methods}

Data Source and Sample

The data source for this study was the Survey of Income and Program Participation (SIPP) 2001, sponsored by the U.S. Census Bureau. The 2001 SIPP was a prospective, longitudinal cohort survey conducted in nine waves, each one collecting information about the previous 4-month interval. The baseline year of the SIPP was 2001, and the SIPP followed individuals for up to 3 years. Face-to-face and telephone interviews collected data on insurance, source and amount of income, labor force participation, program participation and eligibility, general demographics, and disability status. The survey was designed as a multistage-stratified sample of the U.S. civilian non-institutionalized population. All household members age 15 and older were eligible to be interviewed, with proxy response permitted for household members not available at the time of interview $[1,18]$.

Although the SIPP was a longitudinal survey, this study used a cross-sectional design to examine health insurance loss in the follow-up period because the survey does not report origin date of health insurance coverage. Individuals were selected for this study if they were between the ages of 15 and 25 and had insurance coverage at SIPP survey baseline. Members of our sample were also restricted to those who provided information for assessing disability status and provided three full years of data.

The study was approved by the University of Washington Human Subjects Division.

\section{Measures}

\section{Insurance Loss}

Insurance loss was the dependent factor of interest. Individuals who were without insurance at least once for at least 3 months during the 3 -year period of data collection were defined as having lost insurance. An individual had insurance coverage if she reported having private insurance, Medicare, Medicaid, SCHIP, or military-based coverage.

\section{Disability Status}

To create a single disability indicator, we used questions in the SIPP survey from Wave 5, Wave 8, and the labor section. The SIPP survey asked extensive series of questions in Waves 5 and 8 about having difficulty performing functional activities and activities of daily living. If respondents answered yes, they were then asked a series of questions about being unable to perform or needing help to 
perform the functional activities and activities of daily living. For example, a person who reported having difficulty using stairs would then be asked whether she was unable or required assistance to use stairs. The labor force section of the SIPP survey asked each month, "Do you have a physical, mental or other health condition that limits the kind or amount of work you can do?" If a respondent answered yes, then she was asked, "Does your health or condition prevent you from working at a job or business?"

Our final disability indicator was a set of dummy variables for having no disability, non-severe disability, and severe disability. A person without disability reported no activity or work limitations. Persons with non-severe disabilities had difficulty with functional activities and activities of daily living or reported having conditions that limited work for at least 12 months. Persons with severe disability were unable to perform or required assistance to perform functional activities and activities of daily living or reported having conditions that prevented work for at least 12 months.

\section{Personal Characteristics}

The eight additional covariates in the study were gender, race, Hispanic ethnicity, age at baseline (15-18 years, 1922 years, and 23-25 years), insurance type at baseline (private or public), school/work status, poverty status, and state generosity. School/work status was a single variable to show whether respondents were: (1) in school or working full time for the entire 3-year period; or (2) not in school or working full time during the 3-year period. Poverty status, based on family income, showed whether individuals either: (1) lived above federal poverty level for the entire 3-year period; or (2) lived at or below federal poverty sometime during the 3 -year period. The generosity of the state where the survey respondent lived at baseline was represented by a continuous variable that indicated the state's 2001 financial standard (or dollar amount) for a family of four receiving Temporary Assistance to Needy Families benefits [19].

\section{Statistical Analysis}

Descriptive statistics characterized youth who maintained and lost insurance over the 3-year time frame. Significant differences between youth who maintained health insurance and youth who lost health insurance were assessed using chi-square tests.

We conducted logistic regression to calculate the association between disability status and loss of insurance. Adjustment variables were gender, race, ethnicity, age, work or school status, poverty status, type of insurance at study onset, state generosity, and an interaction term between disability and insurance type. Population weights from the Census Bureau adjusting for nonresponse and attrition were used to provide estimates for the U.S. civilian noninstitutionalized population. To determine whether the fitted models adequately described the observed outcomes, we used the Hosmer-Lemeshow global test for goodnessof-fit taking survey design into account [20].

Analyses were conducted using Stata 10.0 (StataCorp, College Station, TX).

\section{Results}

This study includes 2,123 insured youth without disabilities, 320 insured youth with non-severe disabilities, and 295 insured youth with severe disabilities. In total, the 2,738 insured youth in this study represent over 15.96 million insured youth between the ages of 15 and 25 in the U.S. population. Thirty-seven percent of insured youth experienced at least one episode of uninsurance between 2001 and 2004. Thirty-six percent of insured youth without disabilities lost insurance compared to $43 \%$ of insured youth with non-severe disabilities and $41 \%$ of insured youth with severe disabilities $(P=.07)$. Figure 1 shows the cumulative proportion of insured youth who lost insurance over the 3-year period according to disability status.

Youth who lost insurance differed from youth who maintained insurance on personal characteristics. Youth who lost insurance were more frequently covered by public insurance, in the 18-21 age group, and Hispanic. Youth who maintained insurance coverage were more frequently white, working or in school full time, and living above poverty (Table 1).

When assessing the main effect of disability on insurance loss, we find that youth with non-severe disabilities (OR: .91; 95\% CI: .64, 1.29) and youth with severe disabilities (OR: .77; 95\% CI: .52, 1.14) have similar odds of losing insurance compared to youth without disabilities after adjusting for personal characteristics.

In contrast, Table 2 shows estimates for a model that includes an interaction term between disability status and insurance type at baseline. Youth with non-severe disability on public insurance have an estimated $61 \%$ lower odds of losing insurance (OR: 0.39; 95\% CI: 0.16, 0.93; $P=.03$ ) compared to youth without disabilities on public insurance. Further, youth with severe disabilities on public insurance have an estimated $81 \%$ lower odds of losing insurance (OR: $0.19 ; 95 \%$ CI: $0.09,0.40 ; P<.001)$ compared to youth without disabilities.

When examining youth with private insurance, we find that youth with severe disabilities have 1.63 times higher odds (OR: $1.63 ; 95 \%$ CI: $1.03,2.57 ; P=.04$ ) of losing health insurance compared to youth without disabilities. 


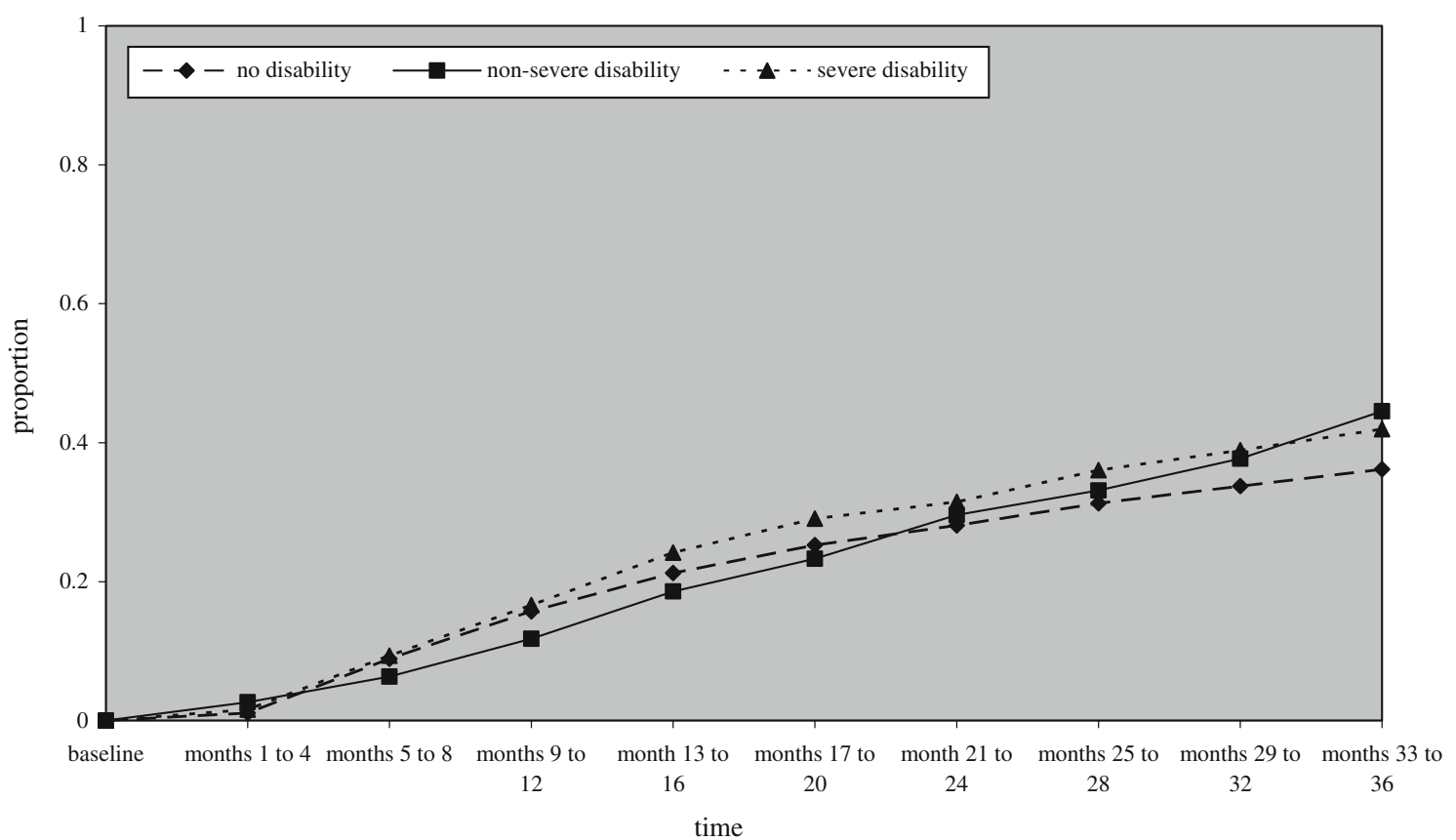

Fig. 1 Cumulative proportion of youth reporting gaps in health insurance coverage, by disability status, 2001-2004

Table 1 Characteristics of insured youth between the ages of 15-25 years, by insurance loss

Source: Survey of Income and Program Participation 2001

$* P<.05$

\begin{tabular}{|c|c|c|}
\hline & $\begin{array}{l}\text { Never lost insurance } \\
(n=1,547)\end{array}$ & $\begin{array}{l}\text { Lost insurance at least } \\
\text { once for at least } 3 \\
\text { months }(n=1,191)\end{array}$ \\
\hline Weighted count & $10,047,339$ & $5,908,167$ \\
\hline \multicolumn{3}{|l|}{ Disability status } \\
\hline No disability & $1242(81)$ & $881(76)$ \\
\hline Non-severe disability & $155(10)$ & $165(13)$ \\
\hline Severe disability & $150(9)$ & $145(11)$ \\
\hline \multicolumn{3}{|l|}{ Type of insurance at baseline* } \\
\hline Private or military & $1357(88)$ & $866(74)$ \\
\hline Public (Medicaid, Medicare, SCHIP) & $190(12)$ & $325(26)$ \\
\hline \multicolumn{3}{|l|}{ Age at baseline* } \\
\hline $15-17$ у.о. & $700(41)$ & 377 (29) \\
\hline $18-21$ у.о. & $493(34)$ & $489(43)$ \\
\hline $22-26$ у.о. & $354(25)$ & $325(28)$ \\
\hline Female & $834(55)$ & $608(51)$ \\
\hline \multicolumn{3}{|l|}{ Race* } \\
\hline White & $1319(83)$ & $913(78)$ \\
\hline $\begin{array}{l}\text { Black, African American, Native American, } \\
\text { Alaska Native, Asian, Pacific Islander }\end{array}$ & $228(17)$ & $278(23)$ \\
\hline Hispanic* & $106(7)$ & $193(16)$ \\
\hline \multicolumn{3}{|l|}{ Work or school status* } \\
\hline Always FT work or school & $796(53)$ & $125(14)$ \\
\hline Sometimes PT or no work or school & $684(47)$ & $967(86)$ \\
\hline \multicolumn{3}{|l|}{ Poverty status* } \\
\hline Always above $100 \%$ FPL & $1042(71)$ & $341(42)$ \\
\hline Sometimes at or below $100 \%$ FPL & $451(29)$ & $695(58)$ \\
\hline
\end{tabular}


Table 2 Associations with losing health insurance during a 3 -year time frame $(n=2,120)$

Source: Survey for Income and Program Participation 2001

$* P<.05$

\begin{tabular}{|c|c|c|c|}
\hline \multirow{2}{*}{ No disability } & \multirow{2}{*}{$\begin{array}{l}\text { Odds ratio } \\
\text { Ref }\end{array}$} & \multicolumn{2}{|c|}{$95 \%$ Confidence interval } \\
\hline & & & \\
\hline Non severe disability & 1.09 & 0.75 & 1.57 \\
\hline Severe disability & 1.63 & 1.03 & 2.57 \\
\hline Private insurance & Ref & & \\
\hline Public insurance* & 2.85 & 1.79 & 4.53 \\
\hline Non-severe disability $\times$ insurance type interaction* & 0.36 & 0.14 & 0.91 \\
\hline Severe disability $\times$ insurance type interaction* & 0.12 & 0.05 & 0.28 \\
\hline Male & Ref & & \\
\hline Female* & 0.72 & 0.58 & 0.88 \\
\hline White & Ref & & \\
\hline $\begin{array}{l}\text { Black, African American, Native American, } \\
\text { Alaska Native, Asian, Pacific Islander }\end{array}$ & 1.21 & 0.90 & 1.63 \\
\hline Non-Hispanic & Ref & & \\
\hline Hispanic* & 2.23 & 1.43 & 3.46 \\
\hline 15-17 age group & Ref & & \\
\hline 18-21 age group* & 1.55 & 1.18 & 2.05 \\
\hline $22-25$ age group* & 1.40 & 1.03 & 1.91 \\
\hline Always above poverty & Ref & & \\
\hline Sometimes at or below poverty* & 2.65 & 2.06 & 3.42 \\
\hline Always FT work or school & Ref & & \\
\hline Sometimes PT work or school* & 5.00 & 3.93 & 6.36 \\
\hline State generosity & 1.00 & 1.00 & 1.00 \\
\hline
\end{tabular}

Youth with non-severe disabilities and youth without disabilities on private insurance have similar odds of losing insurance.

\section{Discussion}

Our descriptive findings and our main effects model indicate that youth with and without disabilities have the same odds of losing health insurance. One possible explanation is that all youth in the 15-25 age range, regardless of disability status, age out of coverage. All youth may subsequently experience difficulty in finding or maintaining full time work or full time school enrollment, both important sources of group health insurance.

However, when we include a multiplicative interaction between insurance type and disability status, we find differences in odds of insurance loss between youth with and without disabilities. Youth with non-severe and severe disabilities on public insurance have lower odds of losing insurance compared to youth without disabilities. This finding may be a result of the three important eligibility pathways that are intended to provide Medicaid coverage to persons with disabilities and special health care needs. First, youth may qualify for Medicaid if they receive cash assistance through the Supplemental Security Income (SSI) program by meeting stringent income requirements and the
Social Security Administration's definitions for disability [21-23]. Second, youth may qualify for Medicaid by meeting the spend-down eligibility criteria for medically needy programs. Eligibility occurs if family income decreases to below state Medicaid eligibility levels after subtracting incurred medical expenses [24]. As of 2003, 35 states ran medically needy programs [25]. Third, some states apply home and community-based services waivers, or 1915(c) waivers, to cover those requiring institutional levels of care, but who remain at home $[23,26]$. Our finding suggests that these eligibility pathways to public coverage offer transitioning youth some protection from insurance loss.

In contrast, youth with severe disabilities on private insurance have slightly higher odds of losing health insurance compared to youth without disabilities on private insurance. To explain this finding, we suggest that youth with severe disabilities age out of parental coverage and experience two possible barriers to obtaining new health insurance coverage. First, youth with severe disabilities do not receive public benefits. They may have incomes that are too high, or families may not be aware or have knowledge of eligibility for public programs. Second, youth with severe disabilities may have reduced access to employer-based coverage because they are less often part of the full-time labor force, make less money, and experience employment discrimination compared to persons without disabilities [27-31]. 
The recent trend in states to provide extended dependent coverage under parents' policies may offer assistance to some youth with disabilities at risk for losing health insurance. As of 2007, 19 states require employers to allow parents to cover their children up to age 24 or 26 as dependents. While these laws help to delay the phenomenon of aging out of coverage, they do not apply to the substantial number of families whose employers selfinsure. Further, in a few states, these laws do not apply if youth, including youth with disabilities, choose not to enroll in school [32].

Medicaid Buy-In may be a useful program to support youth with disabilities who are ineligible for public benefits because they work, but who do not receive workplace benefits. The Ticket to Work and Work Incentives Improvement Act of 1999, the Balanced Budget Act of 1997, and Section 1115 waivers all authorize states to develop Medicaid Buy-In programs, which expand Medicaid eligibility to working adults with disabilities. The programs are offered when jobs: (1) do not offer health insurance, (2) offer health insurance, but individuals do not qualify, or (3) offer health insurance with expensive premiums [29, 33]. States can cover individuals up to $450 \%$ of poverty, and participants pay premiums and copayments based on income [34]. Medicaid Buy-In is also intended to assist persons whose health conditions might improve with services, but whose conditions would deteriorate without services [23].

For Medicaid Buy-In to be effective at stabilizing health insurance for youth with disabilities in transition, policy makers and states must attend to youth enrollment. Only 80,000 individuals between 16 and 64 participated in 2007 [35]. Enrollment ranged from 1 person to 457 persons per 10,000 working-age state residents with a disability between 2000 and 2005 [29]. Enrollment strategies must address awareness because families have reported that no one explained how their children could work and maintain benefits [36].

We identify three areas for future study. We recommend addressing the potentially mediating role of work and school in the relationship between disability and health insurance. Interventions for improving insurance stability among youth could promote educational attainment, which is strongly associated with employment among persons with impairments [37, 38]. Evaluations of education programs, inclusion programs, workplace accommodations, and technologies to increase accessibility and participation should include health insurance coverage as an outcome. Second, future research might explore how youth with disabilities fare based on state residence given differences between states in Medicaid policies and laws on dependent coverage. Finally, additional study of differences by age groups would identify target subpopulations who would benefit from health reforms.
This study is limited in several ways. First, our disability variable is an imperfect measure for non-severe and severe disability. In addition, we treat disability as a static characteristic over 3 years even though it is likely that impairments change over time. We recommend that future studies ask reliable and validated questions to assess disability and disability severity and repeat the questions over time. This would enable researchers to examine how changes in disability severity over time affect insurance status. Our categorization of disability also differs from other definitions of disability and special health care needs [14, 16, 26, 3941]. This explains why our estimates for disability prevalence and uninsurance vary from previous studies $[1,16]$. In the future, our study design and analysis could be repeated using other definitions of disability to compare findings. Previous studies of insurance coverage among youth with disabilities could also be repeated with a definition that distinguishes between non-severe and severe disability.

Second, we do not take into consideration whether individuals changed insurance types before losing insurance coverage. For example, a person who had private insurance at baseline may have changed to public insurance before losing coverage. Future studies could examine interactions between disability and insurance type in the period immediately prior to becoming uninsured. Third, as a cross-sectional study our estimates suggest association only and not causality. Finally, we are unable to examine health insurance stability using a longitudinal approach because the data do not indicate how long participants had insurance coverage when they entered the study. Future studies could be designed using an event history framework for additional research on the process of losing and gaining insurance.

\section{Conclusion}

This study finds that disability severity interacts with insurance type. Youth with non-severe and severe disabilities with public coverage have significantly decreased odds of insurance loss compared to youth without disabilities on public coverage. Public insurance eligibility criteria related to disabilities may prevent youth with disabilities from losing coverage. In comparison, youth with severe disability on private coverage have increased odds of insurance loss compared to youth without disabilities on private coverage. We suggest that increased risk for insurance loss occurs because these youth with severe disabilities do not receive public benefits and experience barriers to obtaining employer-based benefits. Newer state laws that extend dependent coverage under parental insurance and public programs like Medicaid Buy-In may have an important role in supporting all youth with 
disabilities to maintain health insurance during transition into adulthood.

Acknowledgements This study was funded in part by: the National Institute on Disability and Rehabilitation Research (NIDRR), Grant \#H133A060070; Grant Number 1 TL1 RR025016-02 from the National Center for Research Resources (NCRR), a component of the National Institutes of Health (NIH) and NIH Roadmap for Medical Research.

\section{References}

1. Steinmetz, E. (2006). Americans with disabilities: 2002. Current Population Reports, 70-107. http://www.sipp.census.gov/sipp/ p70s/p70-107.pdf. Last accessed April 25, 2007.

2. Havercamp, S. M., Scandlin, D., \& Roth, M. (2004). Health disparities among adults with developmental disabilities, adults with other disabilities, and adults not reporting disability in North Carolina. Public Health Reports, 119(4), 418-426.

3. Dejong, G., Palsbo, S. E., Beatty, P. W., et al. (2002). The organization and financing of health services for persons with disabilities. Milbank Quarterly, 80(2), 261-301.

4. Okumura, M. J., McPheeters, M. L., \& Davis, M. M. (2007). State and national estimates of insurance coverage and health care utilization for adolescents with chronic conditions from the National Survey of Children's Health, 2003. Journal of Adolescent Health, 41(4), 343-349.

5. Young, N. L., Steele, C., Fehlings, D., et al. (2005). Use of health care among adults with chronic and complex physical disabilities of childhood. Disability and Rehabilitation, 27(23), 1455-1460.

6. Hadley, J. (2007). Insurance coverage, medical care use, and short-term health changes following an unintentional injury or the onset of a chronic condition. JAMA, 297(10), 1073-1084.

7. Sommers, A. S. (2006). Access to health insurance, barriers to care, and service use among adults with disabilities. Inquiry, 43(4), 393-405.

8. Hanson, K. W., Neuman, P., Dutwin, D., et al. (2003). Uncovering the health challenges facing people with disabilities: The role of health insurance. Health Affairs (Millwood), W3, 552-565.

9. Collins, S. R., Schoen, C., Kriss, J. L., et al. (2006). Rite of passage? Why young adults become uninsured and how new policies can help. http://www.commonwealthfund.org/usr_ doc/Collins_riteofpassage2006_649_ib.pdf?section=4039. Last accessed May 16, 2008.

10. U.S. Department of Health and Human Services. (2005). Overview of the uninsured in the United States: An analysis of the 2005 Current Population Survey. http://aspe.hhs.gov/health/ reports/05/uninsured-cps/index.htm\#age. Last accessed May 19, 2008.

11. Short, P. F., \& Graefe, D. R. (2003). Battery-powered health insurance? Stability in coverage of the uninsured. Health Affairs (Millwood), 22(6), 244-255.

12. Klein, K., Glied, S., \& Ferry, D. (2005). Entrances and exits: Health insurance churning, 1998-2000. Issue Brief (Commonw Fund), 855, 1-12.

13. Fishman, E. (2001). Aging out of coverage: Young adults with special health needs. Health Affairs (Millwood), 20(6), 254-266.

14. Callahan, S. T., \& Cooper, W. O. (2006). Access to health care for young adults with disabling chronic conditions. Archives of Pediatrics and Adolescent Medicine, 160(2), 178-182.

15. Schwartz, K., \& Schwartz, T. (2008). Uninsured young adults: A profile and overview of coverage options. http://www.kff.org/ uninsured/upload/7785.pdf. Last accessed September 8, 2008.
16. Callahan, S. T., \& Cooper, W. O. (2007). Continuity of health insurance coverage among young adults with disabilities. Pediatrics, 119(6), 1175-1180.

17. Williams, B., \& Tolbert, J. (2007). Aging out of EPSDT: Issues for young adults with disabilities. The Kaiser Commission on Medicaid and the Uninsured Issue Paper, http://www.kff.org/ medicaid/upload/7491.pdf. Last accessed February 27, 2008.

18. U.S. Census Bureau. (2006). Survey of Income and Program Participation (SIPP). http://www.sipp.census.gov/sipp/index.html . Last accessed April 25, 2007.

19. The Urban Institute. (2008). The welfare rules database. http://anfdata.urban.org/WRD. Last accessed April 14, 2008.

20. Archer, K., \& Lemeshow, S. (2006). Goodness-of-fit test for a logistic regression model fitted using survey sample data. The Stata Journal, 6, 97-105.

21. Social Security Administration. (2008). Benefits for children with disabilities. SSA Publication No. 05-10026, http://www.ssa.gov/ pubs/10026.html. Last accessed May 5, 2008.

22. Social Security Administration. (2006). Disability evaluation under social security. http://www.ssa.gov/disability/profes sionals/bluebook/. Last accessed May 5, 2008.

23. Carbaugh, A. L., Elias, R., \& Rowland, D. (2006). Aid to people with disabilities: Medicaid's growing role. Annual Review of Public Health, 27, 417-442.

24. Centers for Medicare and Medicaid Services. (2005). Medically needy. http://www.cms.hhs.gov/MedicaidEligibility/ 06_Medically_Needy.asp. Last accessed September 3, 2008.

25. The Henry J Kaiser Family Foundation. (2003). Medicaid medically needy program enrollment, FFY 2003. http://www. statehealthfacts.org/comparemaptable.jsp ind $=209 \&$ cat $=4$. Last accessed September 3, 2008.

26. Davidoff, A. J., Yemane, A., \& Hill, I. (2004). Public insurance eligibility and enrollment for special health care needs children. Health Care Financing Review, 26(1), 119-135.

27. Pilling, D. S. (2002). Early employment careers of people with disabilities in the National Child Development Study. Work, 18(1), 75-87.

28. Randolph, D. S. (2004). Predicting the effect of disability on employment status and income. Work, 23(3), 257-266.

29. Ireys, H. T., Davis, S. R., \& Andrews, K. L. (2007). The interaction of policy and enrollment in the Medicaid Buy-In Program, 2005. http://www.mathematica-mpr.com/publications/pdfs/ interaction.pdf. Last accessed March 1, 2008.

30. Committee on Disability in America and Board on Health Sciences Policy. (2007). In M. J. Field \& A. M. Jette (Eds.), The future of disability in America. Washington, DC: The National Academies Press.

31. Schur, L. A. (2003). Barriers or opportunities? The causes of contingent and part-time work among people with disabilities. Industrial Relations, 42(4), 589-622.

32. Kronstadt, J., Mojerie, S., \& Schwartz, S. (2007). State efforts to extend dependent coverage for young adults. State Health Policy Monitor, http://www.nashp.org/Files/shpmonitor_depen dentcoverage.pdf. Last accessed September 9, 2008.

33. Sulewski, J. S., Gilmore, D. S., \& Foley, S. M. (2006). Medicaid and employment of people with disabilities: Findings from the national survey of state systems and employment for people with disabilities. Journal of Disability Policy Studies, 17(3), 158165.

34. Mathematica Policy Research Inc. Extending Medicaid to workers with disabilities: The Medicaid Buy-In Program. http://www.mathematica-mpr.com/disability/medicaidbuy-in.asp. Last accessed March 1, 2008.

35. Centers for Medicaid and Medicare Services. (2008). Ticket to Work-Work Incentives Improvement Act (TWWIIA). http:// www.cms.hhs.gov/TWWIIA/. Last accessed March 1, 2008. 
36. Geenen, S. J., Powers, L. E., \& Sells, W. (2003). Understanding the role of health care providers during the transition of adolescents with disabilities and special health care needs. Journal of Adolescent Health, 32(3), 225-233.

37. Zwerling, C., Whitten, P. S., Sprince, N. L., et al. (2002). Workforce participation by persons with disabilities: The National Health Interview Survey Disability Supplement, 1994 to 1995. Journal of Occupational and Environmental Medicine, 44(4), 358-364.

38. Anderson, C. J., \& Vogel, L. C. (2002). Employment outcomes of adults who sustained spinal cord injuries as children or adolescents. Archives of Physical Medicine and Rehabilitation, 83(6), 791-801.

39. Beers, N. S., Kemeny, A., Sherritt, L., et al. (2003). Variations in state-level definitions: Children with special health care needs. Public Health Reports, 118(5), 434-447.

40. Goel, N. L., \& Keefe, R. H. (2003). Medicaid managed care meets developmental disabilities: Proceed with caution. Journal of Health and Social Policy, 16(3), 75-90.

41. McPherson, M., Arango, P., Fox, H., et al. (1998). A new definition of children with special health care needs. Pediatrics, 102, 137-140. 